\title{
FIELD WORK MONITORING AND HERITAGE DOCUMENTATION FOR THE CONSERVATION PROJECT. THE “FORO EMILIANO” IN TERRACINA (ITALY)
}

\author{
Ronchi D. ${ }^{*}$, Limongiello M. ${ }^{2}$, Ribera F. ${ }^{2}$ \\ ${ }^{1}$ Spiron Heritage and Survey, Rome, Italy - diego.ronchi@spiron.it \\ ${ }^{2}$ Department of Civil Engineering, University of Salerno, Italy - (mlimongiello, fribera)@unisa.it
}

Commission II, WG II/8

KEY WORDS: Cultural Heritage, Integration of Active and Passive Sensors, TLS, UAV Photogrammetry, Point Clouds.

\begin{abstract}
:
The area of the "Foro Emiliano", the current "Piazza del Municipio" in the coastal town of Terracina in southern Latium, consists of an articulated group of building belonging to different historical moments. On the roman pavement of the forensic square stand out: a Roman theatre, the urban cathedral, medieval houses, a roman temple and recent buildings dating from the first half of the 20th century. Thanks to recent funding the "Soprintendenza Archeologia, Belle Arti e Paesaggio per le province di Frosinone, Latina e Rieti" has undertaken the demolition of some modern houses insisting on the theatre's porticus post scaenam and began an excavation of the entirely preserved cavea of the Roman theatre building. These interventions of urban archaeology were taken as an opportunity to plan an impressive 3D survey of the historic center, aiming: on one side at monitoring demolition and excavation work, offering a cartographic base for valorization projects, and on the other at the investigation of a vast monumental area. This paper analyses in detail the phases of integration, alignment, filtering and post processing of the acquired data, showing with evidence how the integration of active and passive sensors is the best approach in similar scenario.
\end{abstract}

\section{INTRODUCTION}

Due to the events dating back to the last World War, a large area of the historical city center of Terracina was seriously damaged. The consequent demolition of unsafe buildings, mostly close to the forum, made it possible to highlight numerous Roman monuments. After rubble's evacuation and leveling, and the construction of some containment walls and pedestrian walkways, no major intervention affected the area touched by the war destruction (Coppola, 1984).

This sequence of events has led to a very rare circumstance for a center characterized by life continuity: the elimination of part of the post-ancient buildings that normally seals and makes the historical events of previous eras scarcely probable. This reset, by extreme coincidence, happened in one of the most important areas of the city: the Roman forum. If we consider the built heritage so far brought to light in the Piazza del Municipio in Terracina, and the areas not yet affected by archaeological survey, the extraordinary opportunity available in the field of study and enhancement of historical building is manifested. Such opportunity became the base for the intervention recently undertaken, and not yet concluded, by the Soprintendenza (SABAP Lazio).

To document and highlight the various moments of urban life in the historic center, and to place historical heritage and its aspects of diachronicity in the right place in the restoration project, a choice was made: to include, among the activities to be undertaken systematically, a study of urban and built heritage. The increasingly frequent use in this field of $3 \mathrm{D}$ surveying technologies, allowed to propose a solution based on the integration of the stratigraphic method with such technologies (Dubbini et al 2009; Fiorini et al., 2011; Fiorini et al. 2011; Russo et al 2011). Since this kind of approach to urban areas and built heritage could be defined fruitful and inescapable (Barrile et al., 2015; Remondino et al., 2014), then, in a scenario of constant innovation of sensors and processing software, the application and validation of procedures aimed at defining new quality standards is becoming a priority (Blais, 2004).

\section{HISTORICAL FRAMEWORK AND PROJECT AIMS}

\subsection{Historical framework}

The area of the "Foro Emiliano" (Lugli, 1926), the current "Piazza del Municipio" in the coastal city of Terracina in southern Lazio, consist of a complex group of structures belonging to different construction phases juxtaposed side by side. On the Roman floor of the forensic square, preserved almost in its entirety, numerous ancient structures are still visible next to recent buildings dating back to the 1950 s (Malizia, 2009; Malizia, 2015). This incredible visibility situation, consisting of several construction phases within a modest space of about three hectares, is due to the bombardments that accidentally destroyed, at the end of the Second World War, part of the buildings that insisted on the ancient square of the forum, allowing, however to bring to light important archaeological remains.

The modern square derives its current conformation, albeit with some variations due to successive urban stratifications, from the Roman forum.

This square occupies a partially artificial esplanade, obtained through a leveling system that, resting on vaults, supports it along the southern side (Longo, 2004). The visible open space, sensibly smaller than the Roman one, is nowadays bordered to the west by the capitolium (Valenti, 2016), whose structures were reused for the construction of the cathedral of S. Cesario; to the south, where it is currently the town hall (Coppola, 1984), it was originally a porticoed space; the eastern side, where today the "Palazzo della Bonifica" (Coppola, 1984) is located, was the basilica; on the northern side, behind a porticus post-scaenam, is the roman theatre (Cassieri, 2003; Cassieri, 2004; Cassieri et al. 2012; Innico, 2004). The forum was divided, in the sense of its length, into 
two unequal parts by the passage of the via Appia, whose forensic crossing was marked by two arches: one on the western side, incorporated by the "Palazzo Venditti", and another on the oriental one. Just outside the forensic area, a further temple faces the northern side of the S. Cesario cathedral. The structure, with a tripartite cell and a hollow podium, although dating back to the first half of the I century $\mathrm{AD}$, probably reflects the organization of spaces and road orientations preceding the arrangement above described (Valenti, 2016).

The most ancient building recognizable in the square is the porticus, which later became the theater's porticus postscaenam, built at the beginning of the I B.C. The subsequent construction of the theater with respect to the previous organization of the forum is evidenced, in addition to the numerous noticeable interventions on the porticus, by the abrupt interruption of the paved road that passes behind the nearby three-celled temple.

This older structure owes its present isolation to not being included in the most recent accommodation. The forensic pavement, which preserves the dedicatory inscription of Aulo Emilio, who lived between the Augustan and Tiberian periods, can also be dated to the first half of the I. A.D. There are several dating hypotheses regarding the complex substructures of the forum, currently under study, whose chronology fluctuates between the late republic and the Neronian age. The chronology of the other monuments that border the short sides of the forum are consistent with the chronology of both capitolium and basilica, also dating in the first half of the I AD. The eastern access to the square was marked by a four-sided archway, which gives us the ancient dimensions of the square. Between the four-sided arch and the back wall of the porticus post-scaenam there are remains of a hexastyle temple (s.c. temple of via Pertinace), a structure that probably represents the last intervention on the forum (Innico, 1998).

\subsection{Aims}

The surveying project at the Foro Emiliano had two main goals: one technical and one methodological, which were then declined in various objectives determined by specific needs expressed by the valorization project of the area and by that of scientific and archaeological investigation. These two main goals were: the facilitation of restoration project activities on one hand, and the documentation of historical buildings and their modifications on the other (Barba et al, 2012). The first objective of this knowledge and documentation project was then the accurate description of the volumes and surfaces of the city center. This objective was achieved through the integration of various active and passive surveying technologies, which allowed to reach a remarkable descriptive quality for the area (Beraldin, 2004; Caprioli et al., 2011; Carpiceci 2012). A particular preliminary need was the accurate estimation of the volumes of land to be removed. This evaluation preceded the drafting of the actual project, allowing economic and technical evaluations related to field activities and procedures for disposal of the removed material. Combined with this need to describe the actual state of the area, considering how the project foresees the demolition of a small building and a vast excavation of the stratigraphies that occupy part of the cavea and part of the porticus post - scaenam, excavation and demolition monitoring needs were expressed. This type of requirement was, in turn, declined in periodic surveying activities with laser scanners, aerial photogrammetry, and systematic documentation of the archaeological excavation through photogrammetric survey procedures.

The periodic documentation of the entire area was agreed with the Soprintendenza, identifying four cornerstones of the project to be totally recorded: 1) present state before the interventions; 2) post-demolition; 3) ending of archaeological excavations; 4) ending of restoration project. This multitemporal monitoring of the area provides for the delivery of georeferenced general orthophotos with a minimum resolution of $5 \mathrm{~cm} / \mathrm{px}$, vectorial maps in different scale and the delivery of point clouds registered within a homologous coordinate system.

The documentation of the archaeological excavation, specifically the graphic one composed of layers maps, this will be systematically realized through close range photogrammetry and managed within GIS. In addition to the evaluation of the volume of material to be removed, the preliminary survey activities were used to map facades with high precision, in order to evaluate restoration and consolidation interventions already necessary during the preliminary phase.

The survey project, intended as an open knowledge management system for an area, proved once again to be the perfect opportunity to proceed with a meticulous organization, systematization and expansion of historical knowledge for the area.

The aim of such knowledge project is the creation of diachronic maps for accurate recording and immediate reading of building stratification and the elaboration of façade's photomaps with the identification of the stratigraphic units. The integration of survey instruments, in this case a camera with APS C sensor, a Leica BLK360 and a CAM2 Faro Focus X330, took place both using points measured with Geomax Zenith 20 GPS and through cloud to cloud registering procedures.

In particular, the most resolute point cloud obtained with Faro laser scanner was used as a "reference" cloud to register integration scans performed with the Leica BLK 360. The urban canyon situation prevented an optimal use of the GPS antenna, for this reason the point clouds obtained by photogrammetric triangulation, in addition to taking advantage of these measurements, were also recorded with a cloud to cloud procedure, obtaining better recording results.

\section{DATA ACQUISITION AND PROCESSING}

\subsection{Case Study}

The 3D surveying of the Foro Emiliano of Terracina concerned an area measuring about three hectares steeply sloping from North West to South East, characterized by a maximum height difference, between ground level and roofs, of about $30 \mathrm{~m}$ (Fig. 1). This factor had to be taken into account during the planning phase in order to obtain an average GSD compliant with the bidimensional elaborates to be delivered. The urban fabric with a continuity of life, with alleys of modest width, often less than $2 \mathrm{~m}$ it represented a further critical factor both in the topographic and photogrammetric survey phase.

In particular, the use of GPS in the narrowest alleys has been extremely problematic.

The case study, in addition to validating the approach chosen to integrate different sensors, showed how the elasticity of photogrammetry integrates and compensates for the expeditiousness of laser scanning. 


\subsection{TLS Survey}

The aim of Terrestrial Laser Scanner (TLS) surveying technology in this case was the creation of a dense and accurate point cloud, for subsequent integration with the aerophotogrammetric point cloud. Moreover, TLS is irreplaceable for surveying narrows spaces often founded in long living urban areas. In this scenario, two distinct terrestrial laser scanners were used: a long-range TLS and a medium range one (Jaafar, 2017). The long-range TLS used was the Faro Focus X330 (range $0.6 \mathrm{~m}-330 \mathrm{~m}$, Max measurement speed 976.000 points / second, HDR integrated camera, Field of view 300 - $360^{\circ}$ (vertical - horizontal), Ranging Error $4 \mathrm{~mm}$ (a) 10m). The acquisition phase included 31 scan positions, obtained in 1 working days (approximately 8 hours in the field). The weather conditions were partially cloudy, guaranteeing diffuse lighting on the theatre, an ideal condition to capture RGB data. In order to facilitate alignment, where possible, we used spherical targets of 7.5 $\mathrm{cm}$. radius mounted on a support (tripod) to improve visibility from scan positions. A sufficient overlap is a needed condition during the alignment, since the algorithm used is based on the geometry of overlapping areas between scans. A sufficient overlap means that the surface can be digitized from several directions and an increase in the overall sampling density and data redundancy. The resolution for each scan was chosen considering its distance from the center of the scene. For the most distant scanning positions from the archaeological area, and in particular from the theatre, a resolution value of $3 \mathrm{~mm}$ at $10 \mathrm{~m}$ was chosen, while, for closer scan positions, the resolution was $6 \mathrm{~mm}$ at $10 \mathrm{~m}$. The medium range TLS was a Leica BLK360 (range $0.6 \mathrm{~m}-60 \mathrm{~m}$,
Max measurement speed 360.000 points / second, HDR integrated camera, Field of view $300-360^{\circ}$ (vertical horizontal), Ranging Error 6mm @10m / 8mm @ 20m). The BLK is controlled by a tablet, connected to it through Wi-Fi, running the Autodesk app Recap Pro. The operational phase on the field for the acquisition of data is simplified, accessible also for non-expert users, and part of the data processing can be completed directly on the field using the tablet. Size and maneuverability of the BLK360 are key factors for the application of this sensor in survey activities for Cultural Heritage. The Leica BLK360 was used only in the theatre area: the acquisition phase included 26 scan positions obtained in 1 working days (approximately 6 hours in the field). Scan resolution was set to high mode (5 mm @ $10 \mathrm{~m}$ ). During the acquisition, weather conditions were as cloudy as during the acquisition with Faro Focus, but in this acquisition, spheres were not used.

The objective, given the multi-temporal monitoring purpose, was to obtain a base point cloud representing a wide area (the one obtained with the Faro Focus 3D X330), that will be regularly updated, using only Leica BLK360 and photogrammetry, at various stages of the restoration and excavation project. This choice of using only the most manageable and faster tools, was made in order to have a regular and accurate documentation acquired in a timely convenient manner. In order to integrate and validate data precision and accuracy, it is necessary to acquire, with both instruments, a common area, in this case the Roman theater. Figure 2 shows the TLS stations and the scan resolution for each scan.

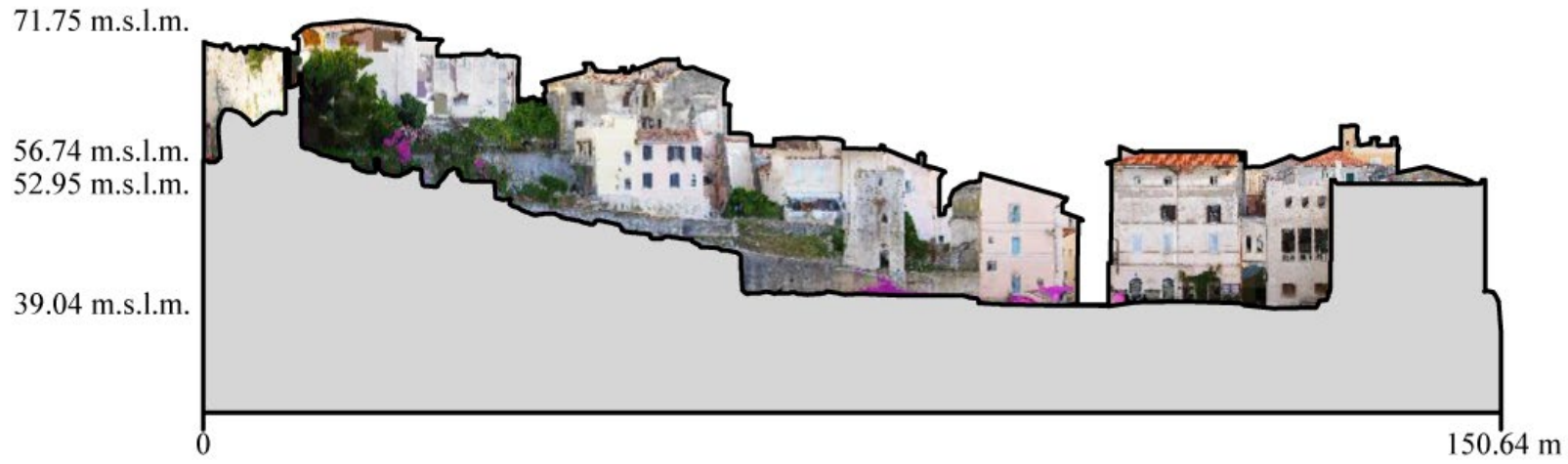

70.28 m.s.l.m.

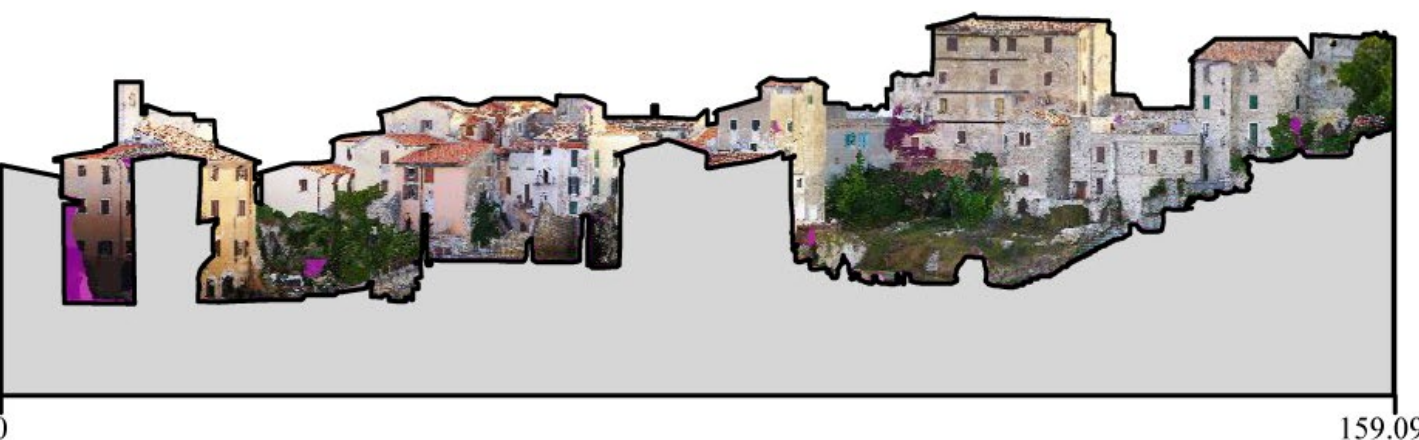

$159.09 \mathrm{~m}$

Figure 1: Cross sections 


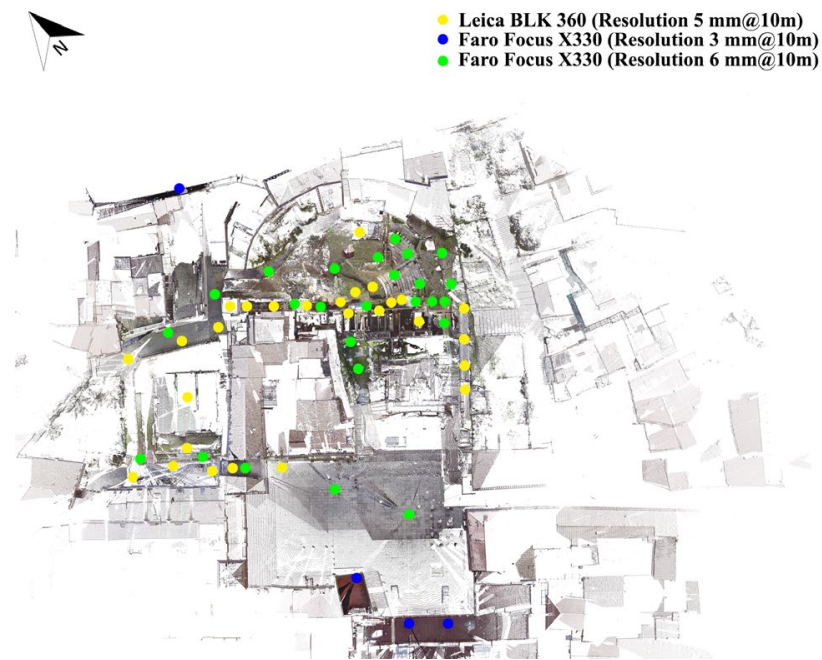

Figure 2: Positions of the X330 scans (green and blue) and the BLK360 scans (yellow)

\subsection{UAV Photogrammetry Survey}

The UAV used for this application is an assembled hexacopter (Fig. 2) with a net weight of about $2.5 \mathrm{~kg}$ and maximum payload of $1 \mathrm{~kg}$. The camera used for capturing the set is a mirrorless Sony alpha 6500 with 24-megapixel APS-C sensor (6000 x 4000 pixels, 23.5 x $15.6 \mathrm{~mm}$ and a Pixel Size of $3.96 \mu \mathrm{m})$ and a fixed Sony EMount lens (16 mm focal length, Field of View - FOV $\left.83^{\circ}\right)$. For the acquisition of photogrammetric shots, a double capture mode was chosen: a first one using automatic flight plan for pseudonadiral photogrammetric shots, and a second in manual mode with the camera's axis inclined of about $45^{\circ}$ in order to record facades too. Survey flight-lines were pre-programmed via DJI GroundStation software. For the pseudo-nadiral acquisition, the UAS was set to a target altitude of $107 \mathrm{~m} \mathrm{(60} \mathrm{m} \mathrm{above} \mathrm{the} \mathrm{horizontal} \mathrm{plan} \mathrm{of}$ the theatre). The altitude is calculated by DJI Ground-Station software using elevation grid derived from Google Earth. Parallel flights lines were planned, setting some camera parameters (dimensions of the sensor and focal length), in order to have a $70 \%$ of image overlap and a $60 \%$ of sidelap. The intervalometer was set to shot every 2 second along all flight paths, the horizontal ground speed, $4.0 \mathrm{~m} / \mathrm{s}$, resulted in an image capture approximately every $8 \mathrm{~m}$. The camera was set to aperture-priority mode, and used an $\mathrm{f} / 8 \mathrm{~s}$ for pseudo - nadiral shots and $\mathrm{f} / 5.6$ for oblique images. The UAS had a flight-time of about $\sim 11 \mathrm{~min}$, using two lithium polymer battery $(11 \mathrm{Ah}, 22.2 \mathrm{~V}, 6 \mathrm{cel})$, while carrying the described payload. A generous overhead ( $\sim 4 \mathrm{~min})$ was spared in order to safely land the UAV. The image acquisition was planned bearing in mind project requirements - a GSD of about $1.5 \mathrm{~cm}$ and, at the same time, with the aim of guaranteeing a high level of automation in the next step of data elaboration.

The acquired images, in total 324, are divided in 280 pseudo-nadiral shots obtained in automatic flight, and 44 images taken in manual flight with the camera inclined at $45^{\circ}$. The nadiral flight had a southeast to north-west direction, covering an area of approximately $88.5 \times 58.5 \mathrm{~m}$. The manual flight with the tilted camera, at an average flight altitude of $28 \mathrm{~m}$, was not carried out systematically, offering a non-constant coverage.

Figure 3 shows the positions of the photogrammetric shots. Acquired images were processed in a single project containing Nadir and oblique images (280 and 44 respectively).

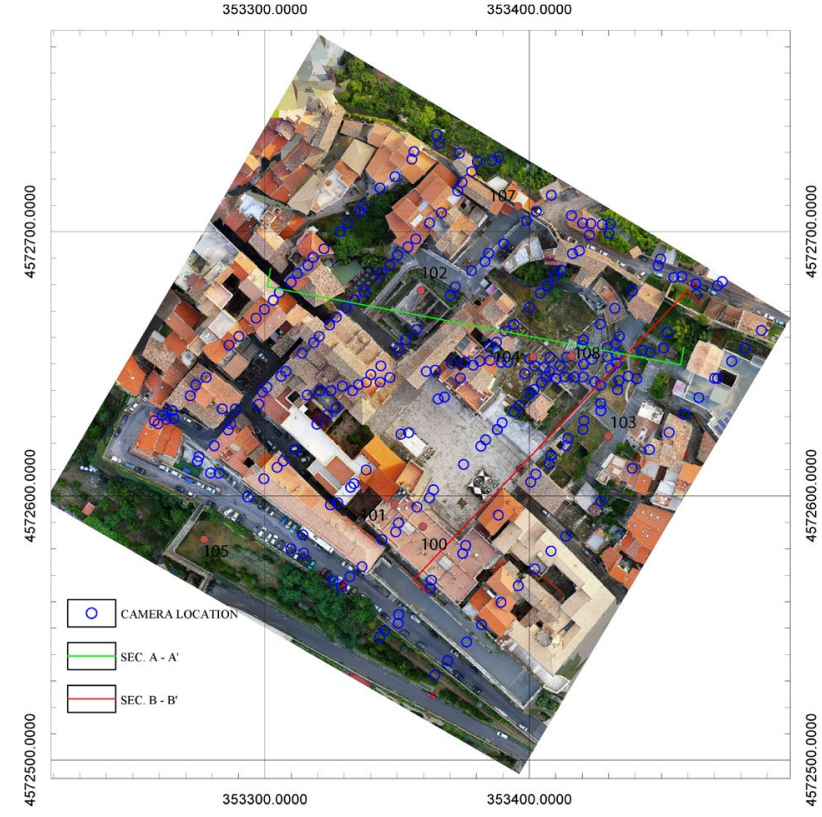

Figure 3: Orthophoto, photogrammetric shots (blue), lines sections (green and red), GCPs and CPs (red)

\subsection{GCPs acquisition}

Topographic measurements were taken on photogrammetric targets (size $40 \times 40 \mathrm{~cm}$, red and black with triangular contrast elements), fixed with topographic nails, well distributed over the surveyed area, placed on flat surfaces, without covering archaeological targets. Ground control points (GCP) have been measured with nRTK mode.

The instrumentation used to measure each target consists of a Geomax Zenith 20 antenna with a built-in receiver. The GNSS survey referred to the Italian geodetic and cartographic System UTM/ETRF00 DATUM for planimetric coordinates and the geoid model ITALGEO2005 provided by the IGMI (Istituto Geografico Militare Italiano) for vertical values relative to mean sea level.

For measuring GCPs in nRTK mode, measurement uncertainty of $1 \mathrm{~cm}$ in planimetry and 1.5 in altimetry was accepted. The GCPs were then imported into a photogrammetric software to georeference point cloud, 3D model and orthophotos.

A total of 8 points were measured: 4 used as GCP $(101,102$, 105 and 108), while the remaining 4 used as Check Point (CP, 103, 104, 106 and 107). The GCPs and CPs served, in addition to the georeferencing, also for the self-calibration phase and estimation of internal and external parameters.

\subsection{TLS processing}

The two TLS data sets were processed using the software solution suggested by the manufacturers: Faro Scene 2019 for the Focus X330 and Autodesk Recap Pro for BLK360. For both software solutions, the fundamental algorithm on which the scan registration is based is the minimization of the cloud to cloud distances through an ICP algorithm (Iterative Closest Point). The alignment and registration solutions offered by this two software are similar, however, at least the initial phase is different. In Scene 2019, the operator decides whether to directly carry out a cloud to cloud alignment or whether to previously perform a roto-translation between individual scans 
in a local coordinate system by identifying homologous points in overlapping areas. In order to reduce the registration time, it is possible to automatically identify standardized external references (spheres and / or target planes), for the identification of homologous points between scans. In Autodesk software, the first approach proposed is a fully automatic registration, which, by looking for correspondences between all scans, requires a large computational time. If the procedure is only partially successful, the software allows manual identification of targets and natural homologous points, to reduce distance among contiguous scans, improving their alignment using ICP algorithm. The thirty-one TLS scans acquired by Faro Focus 3D X330 were co-registered and subsequently aligned to build a global point cloud of the theatre using Faro Scene 2019 for coregistration and global alignment. The final point cloud is about 800 million points large. For the co-registration between scans, the mean point error on reference pairs is $4.4 \mathrm{~mm}$, with maximum error of $18.8 \mathrm{~mm}$, in correspondence of the scans with minimum overlap (about 20\%). The twenty-six scans acquired with Leica BLK360 were registered together in Autodesk Recap Pro. To standardize registration methodology with the clouds from the Faro laser scanner, the single scans of the BLK, once aligned in Autodesk Recap Pro, have been individually imported into Scene 2019, and re-aligned by cloud to cloud registration command. The total point cloud is about 510 million large. Using cloud to cloud registration between scans, the mean point error on reference pairs is $13 \mathrm{~mm}$, and maximum error of $50.2 \mathrm{~mm}$, in correspondence of scans with overlapping for about $46.6 \%$. To georeference point clouds it has been used CloudCompare software package, ver. 2.10 (Girardeau-Montaut, 2011) using natural points measured with GNSS techniques.

\subsection{UAV Processing}

The photogrammetric set has been processed using Agisoft Metashape (ver. 1.5.1 build 7618). The following parameters were set during the process: in the 'Align Photos' phase, Accuracy = Highest (original images), Key-Point limit $=60000$, Tie-Point limit $=60000$. To optimize camera alignment process, $\mathrm{f}$ (focal length), cx and cy (principal point offset), k1, k2, k3 (radial distortion coefficients), p1, p2 (Tangential distortion coefficients) and b1, b2 (Affinity and Skew transformation coefficients) were fixed by means of a self calibration procedure. For the Dense Cloud computation, the parameters used were: Quality $=$ High ( $1 / 2$ of the original images), Depth filtering = Disable; once the complete elaboration of the photogrammetric shots was done, the software gave back the texturized 3D model of the Terracina theatre, used to produce orthophoto and DSM. The analysis of georeferencing residuals on GCPs, the RMSE estimated on the coordinates and their combination are reported in Table 1. It can be outlined that the average error on GCPs is about $5.2 \mathrm{~cm}$, while on the CPs the average error is $6.4 \mathrm{~cm}$.

\section{RESULT AND DISCUSSION}

\subsection{Quality assessment of the products}

For the characterization and validation of the outputs obtained from different sensors, some comparisons have been made between the generated point clouds. A first analysis was carried out on the density of the data: in particular, the theater area was analyzed to check density variation between point clouds. It should be emphasized that the density for active sensors is strongly dependent on scanning resolution set during data acquisition phase and from the distance from the scanned object, while for photogrammetry the quantity of data depends, in addition to the resolution of the images, from the processing parameters for dense cloud generation.

Density evaluation can be useful to understand how data is different from one another and therefore in their integration. From the above, it is clear that, due to the acquisition geometry and generation procedure, the aerial photogrammetric cloud is more homogeneous than that produced by TLS. The highest density was obtained with the Leica BLK360, with which however a smaller survey area was covered, about a half compared to that surveyed with the CAM 2 Faro Focus X330.

The density (Number of neighbours) is calculated by N. pt/ analyzing a circumference with a radius of $0.564 \mathrm{~m}$ (circumference area about $1 \mathrm{~m}^{2}$ ).

The estimated density was calculated on a sample area of about $3000 \mathrm{~m}^{2}$, containing some facades of adjacent buildings (municipality and tower).

Table 2 shows the characteristics of the point clouds elaborated. To assess the accuracy of the sensors, a cloud to cloud comparison was made between point clouds generated and geo-referenced in the same reference system. The data presented are only concerning the façade of the tower placed beside the municipality.

The results were filtered assuming a maximum threshold of 5 $\mathrm{cm}$. For the calculation of the average of the residuals $(\mu)$ and of the standard deviation $(\sigma)$, a Gaussian type frequency distribution has been assumed. The frequency distribution assumed for the residues between the point clouds was the Gaussian one. The values of $\mu$ and $\sigma$ are reported in Table 3 . In Figure 4, the Gauss curves of the three comparisons have been represented on the same scale. The results of distances between clouds are comparable to similar studies (Calantropio et al, 2018).

\begin{tabular}{|c|c|c|c|c|}
\hline GCP & Xerror $(\mathrm{cm})$ & $Y_{\text {error }}(\mathrm{cm})$ & $Z_{\text {error }}(\mathrm{cm})$ & Total $(\mathrm{cm})$ \\
\hline 101 & 2.2 & 0.7 & 3.4 & 3.4 \\
\hline 102 & 2.1 & 0.7 & 9.0 & 9.0 \\
\hline 105 & 1.3 & 0.7 & 4.4 & 4.4 \\
\hline 108 & 3.1 & 0.7 & 4.1 & 4.1 \\
\hline RMSE & 2.2 & 0.7 & 5.2 & 5.2 \\
\hline CP & $\mathrm{X}_{\text {error }}(\mathrm{cm})$ & $\mathrm{Y}_{\text {error }}(\mathrm{cm})$ & $Z_{\text {error }}(\mathrm{cm})$ & Total $(\mathrm{cm})$ \\
\hline 100 & 0.9 & 3.5 & 3.5 & 5.0 \\
\hline 107 & 2.9 & 12.4 & 5.4 & 6.2 \\
\hline 103 & 1.9 & 1.9 & 2.9 & 4.0 \\
\hline 104 & 0.8 & 10.5 & 0.4 & 10.5 \\
\hline RMSE & 1.6 & 7.1 & 3.1 & 6.4 \\
\hline
\end{tabular}

Table 1: Residuals on GCPs and CPs

\begin{tabular}{|c|c|c|c|c|}
\hline & $\begin{array}{c}\text { P.Cloud } \\
(\mathrm{Mil} . \mathrm{pt})\end{array}$ & $\begin{array}{c}\mu_{\text {density }} \\
\left(1000 \mathrm{pt} / \mathrm{m}^{2}\right)\end{array}$ & $\begin{array}{c}\sigma_{\text {density }} \\
\left(1000 \mathrm{pt} / \mathrm{m}^{2}\right)\end{array}$ & $\begin{array}{c}\text { Area } \\
\left(\mathrm{m}^{2}\right)\end{array}$ \\
\hline $\begin{array}{c}\text { UAV with } \\
\text { mirrorless }\end{array}$ & 205.325 & 1.202 & 0.156 & 71,99 \\
\hline $\begin{array}{c}\text { CAM2 Faro } \\
\text { Focus3D } \\
\text { X330 }\end{array}$ & 779.923 & 26.724 & 21.650 & 25,20 \\
\hline $\begin{array}{c}\text { Leica } \\
\text { BLK360 }\end{array}$ & 510.377 & 36.010 & 23.462 & 11,70 \\
\hline
\end{tabular}

Table 2: Main specifications of the TLS and aerial photogrammetric point clouds 


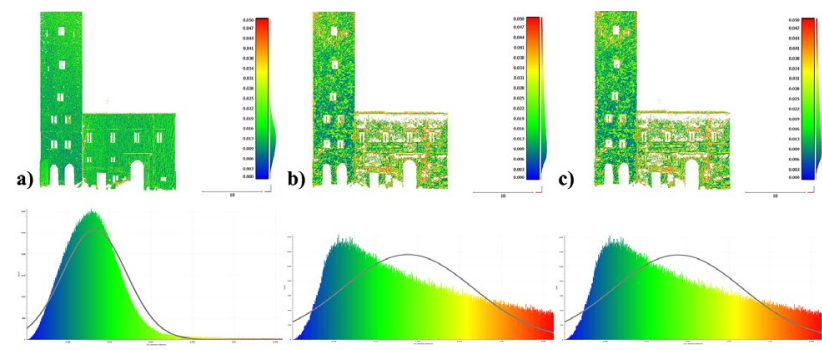

Figure 4: $\mathrm{C} 2 \mathrm{C}$ analysis between point clouds: a) CAM2 Faro Focus X330 VS Leica BLK360; b) CAM2 Faro Focus X330 VS photogrammetric cloud by Sony alpha 6500 ; c) Leica BLK360 VS photogrammetric cloud by Sony alpha 6500

\subsection{Volume calculation}

For project's purposes, the volume of land occupying the theatre's cavea had to be calculated. The calculation methodologies has been chosen according to ground's lying conditions, in fact the position of the ground's lower face is not flat but, covering the seats of the theatre, it has a specific shape, a shape that had to be reconstructed (Fig. 5). In order to have a back face of the soil layer as close as possible to reality, the entire extension of the theater cavea was modeled in $3 \mathrm{D}$, starting from the visible part and reconstructing its extension with a curve projection.

After registering the 3D model with surveyed data, within cloud compare software, the reconstructed surface was coated with a point cloud, which was than segmented and joined to the superior layer face. The point cloud was then transformed into a mesh with the Poisson algorithm and the volume derived from it. To ensure a greater accuracy in measuring the volume of the ground covering the theatre's cavea, we proceeded with manual extraction of sections, verifying directly the volume previously calculated.

Volume comparison from data obtained from different sensors was carried out with the Surfer software. This software provides three numerical integration methods for calculating volume using the Trapezoidal rule, Simpson's rule, and Simpson's 3/8 rule (Chen et al, 2017). The comparison between the results assumed that the three computations should have differed by less than $1 \%$, considering the actual volume included within this range. In the event of major discrepancies, it would have been necessary to proceed with the generation of terrain models with a denser mesh.

\begin{tabular}{|c|c|c|}
\hline & $\mu(\mathrm{cm})$ & $\sigma(\mathrm{cm})$ \\
\hline CAM 2 Faro Focus X330 VS Leica BLK360 & 1.6 & 0.5 \\
\hline CAM 2 Faro Focus X330 VS Hexacopter & 2.0 & 1.0 \\
\hline Leica BLK360 VS Hexacopter & 2.2 & 1.0 \\
\hline
\end{tabular}

Table 3: Cloud to Cloud absolute distance computation $(<5 \mathrm{~cm})$

\begin{tabular}{|c|c|c|}
\hline & $\begin{array}{c}\text { Leica } \\
\text { BLK360 }\end{array}$ & $\begin{array}{c}\text { CAM 2 } \\
\text { Faro Focus X330 }\end{array}$ \\
\hline Trapezoidal & 524.61 & 523.61 \\
\hline Simpson's & 524.12 & 523.84 \\
\hline Simpson's 3/8 & 524.07 & 523.55 \\
\hline Positive Vol. & 568.35 & 567.67 \\
\hline Negative Vol. & 23.52 & 23.06 \\
\hline
\end{tabular}

Table 4: Estimate of underground volumes

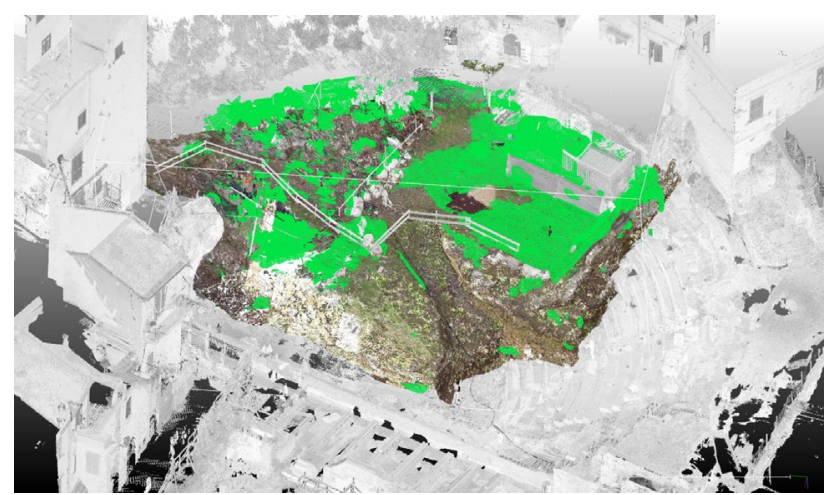

Figure 5: Mesh to Mesh volume estimation

In this application, the resolution of the mesh was set by 5 $\mathrm{cm}$. The results are reported in Table 4 . The volumes reported are in $\mathrm{m} 3$. It should be noted that the volume calculation is greater $(1 \mathrm{~m} 3)$ using the cloud coming from Leica BLK360. This is possible due to the presence of some mobile objects on the site, not yet there while scanning with Faro. Consequently have been acquired only with BLK360, and subsequently triangulated and computed in the volume.

\section{CONCLUSIONS}

The 3D survey at the "Foro Emiliano" in Terracina, considering the complexity of the urban fabric, with its alleys, vaulted streets, conspicuously high buildings in relation to the walkways, the wall textures preserving incredible quantities of building stratifications, has confirmed once again the need and fruitfulness of procedures that integrate active and passive sensors. To precision and logistics, expeditiousness and repeatability must be added, even in a context of considerable extension and penalizing orography, so as to give hope in the definition for a qualitative standard for this kind of intervention.

The advantages highlighted by the procedures deployed are considerable and not limited to the project phases only, but to the set of activities that transform the measurement activity in historical centers into a knowledge project.

The integration of active sensors with noticeably different range rates has made it possible to obtain higher resolutions where it was strictly required, and smaller resolutions to map the context in which the archaeological area was located. The use of photogrammetry by UAV has made it possible to obtain an accurate description for the roofs, which are not easily detectable by active sensors due to the continuous altitude changes and the difficulty of having appropriate scan locations. The precision of the integration of the point clouds achieved has allowed the realization of the graphic drawings required by the SABAP Lazio with scale details between 1:50 and $1: 20$. Furthermore, the establishment of a basic cartography that can be integrated with subsequent scans and photogrammetric surveys will constitute an incredibly versatile documentation in the course of imminent archaeological excavations.

For this phase we will in fact map each stratigraphic units with photogrammetry, from which the two-dimensional elaborates characteristic of the archaeological excavation (maps and sections) will be derived, adding to that, for each removed layer, orthophotos and DEM.

This approach will also be used in terms of managing the excavation documentation, which will be integrated into a GIS system. 


\section{ACKNOWLEDGEMENTS}

The survey of Foro Emiliano in Terracina was supported by "Soprintendenza Archeologia Belle Arti e Paesaggio per le province di Latina Frosinone e Rieti" (SABAP Lazio) - official responsible Dr. F. Di Mario. The authors would like to thank the drone pilot Rocco D'Auria (RDigital) for the collaboration in the images acquisition by the UAV.

\section{REFERENCES}

Barba, S., Barbarella, M., Di Benedetto, A., Fiani, M., and Limongiello, M., 2019. Quality assessment of UAV photogrammetric archaeological survey. In: Int. Arch. Photogramm. Remote Sens. Spatial Inf. Sci., Vol. XLII2/W9, pp. 93- 100.

Barba, S., De Feo, E., D'Auria, S., and Guerriero, L., 2012. Survey and virtual restoration: The Castle of Magacela (Spain). In: 2012 18th International Conference on Virtual Systems and Multimedia, pp. 641-644, IEEE.

Barrile, V., Bilotta, G., Lamari, D., Meduri, G.M., Monardi Trungadi, U., Ricciardi, A., 2015. Computer vision/structure for motion per la diffusione dei beni culturali. In: Atti della XIX Conferenza ASITA, Milano, pp. 51-60.

Beraldin, J.A., 2004. Integration of laser scanning and closerange photogrammetry. The last decade and beyond, in Proceedings of the $\mathrm{XX}^{\circ}$ ISPRS Congress, Commission VII, Istanbul, pp. 972-983.

Blais, F., 2004. Areview of 20 years of range sensors development. In: Journal of Electronic Imaging, Vol. XIII, I, pp. 231-240.

Calantropio, A., Chiabrando F., Rinaudo F., Teppati L., 2018. Use and evaluation of a short range small quadcopter and a portable imaging laser for built heritage 3D documentation. In: The International Archives of the Photogrammetry, Remote Sensing and Spatial Information Sciences, Vol. XLII-1, ISPRS, Karlsruhe, Germany, pp. 71-78.

Caprioli, M., Minchilli M., Scognamilio, A., 2011. Experiences in photogrammetric and laser scanner surveing of architectural heritage. In: Geoinformatics FCE CTU, pp. 55-61.

Cassieri, N., 2003. Il complesso del teatro-portico di Terracina. Prime acquisizioni. Lazio e Sabina 2, pp. 277-288.

Cassieri, N., 2004. Le indagini nel complesso del teatro-portico di Terracina. Scienze dell'antichità. Storia, archeologia, antropologia 12, pp. 509-525.

Cassieri, N., Innico, P. C., 2012. Terracina - Foro Emiliano: Il Tempio Maggiore Nella Cattedrale Di S. Cesareo." Lazio E Sabina 8, pp. 429-434.

Carpiceci, M., 2012. Fotografia digitale e architettura. Storia, strumenti ed elaborazioni con le odierne attrezzature fotografiche ed informatiche, Roma (Italy).

Coppola, M. R., 1984. Il foro emiliano di Terracina. Rilievo, analisi tecnica, vicende storiche del monument, MEFRA 96, pp. $325-375$.
Fiorini, A., Archetti, V., 2011. Fotomodellazione e stereofotogrammetria per la creazione di modelli stratigrafici in archeologia dell'architettura. In: Archeologia e Calcolatori, Vol. XXII, pp. 199-216.

Fiorini, A., Urcia, A., 2011. V. Archetti, The Digital 3D Survey as Standard Documentation of the Archaeological Stratigraphy. In: M. Dellepiane, F. Niccolucci, S. Pena Serna, H. Rushmeier, L. Van Gool (edd.), VAST, The 12th International Symposium on Virtual Reality, Archaeology and Cultural Heritage, Goslar, pp. 145-152.

Girardeau-Montaut, D., 2011. CloudCompare - Open Source project. Available from http://www.cloudcompare.org/.

Innico, P.C., 1998. Contributo alla definizione dell'assetto monumentale del foro emiliano a Terracina: un antico edificio in via Pertinace, in AA.VV. Studi in onore di A. Bianchini. In: Atti del III convegno organizzato dalla Società di Storia Patria della provincia di Latina, pp. 150-168.

Innico, P. C., 2004. Il teatro romano di Terracina nella forma della città antica. Scienze dell'antichità. Storia, archeologia, antropologia 12, pp. 591-611.

Jaafar, H.A., 2017. Detection and Localisation of Structural Deformations Using Terrestrial Laser Scanning and Generalised Procrustes Analysis. Ph.D. Thesis, University of Nottingham, Nottingham, UK.

Longo, P., 2004. "Per Un Nuovo Inquadramento Cronologico Del Foro Emiliano E Del Suo Impianto Sostruttivo." Scienze Dell'antichità. Storia, Archeologia, Antropologia 12, pp. 613-621.

Lugli, G., 1926. Ager Pomptinus, 1: Anxur-Tarracina. Roma, pp. $85-96$.

Remondino, F., Campana, S., 2014. 3D Recording and Modelling in Archaeology and Cultural Heritage. Theory and Best Practices, Oxford.

Russo, M., Remondino, F., Guidi, G., 2011. Principali tecniche e strumenti per il rilievo tridimensionale in ambito archeologico. In: Archeologia e Calcolatori, Vol. XXII, pp. 169-198.

Valenti, M., 2016. Il Capitolium e il Tempio Maggiore di Terracina. Due esempi di podi templari a sostruzione cava. Caratteristiche tecnico-formali, funzione e terminologia. In: L'Architettura del sacro in età romana : paesaggi, modelli, forme e comunicazione, pp. 49-62. 